\title{
Letter to the Editor: Laser Enhancements After Surface Ablation
}

\author{
Laura de Benito-Llopis (D) - Miguel A. Teus
}

Received: February 10, 2021 / Accepted: June 24, 2021 / Published online: July 9, 2021

(c) The Author(s) 2021

Keywords: Photorefractive keratectomy; PRK; Laser-assisted subepithelial keratectomy; LASEK; Surface ablation; Laser enhancements; Laser retreatments; Mitomycin C; MMC

\section{Key Summary Points}

Surface ablation to treat residual refractive errors after previous laser surface treatments has been proved to be safe and effective.

This article is based on previously conducted studies and does not contain any new studies with human participants or animals performed by any of the authors.

We read with interest the article by Moshirfar et al. [1] about photorefractive keratectomy (PRK) enhancements following primary PRK. They show good results with the technique, which supports the well-established practice worldwide of retreating residual refractive errors

L. de Benito-Llopis $(\varangle)$

Moorfields Eye Hospital NHS Foundation Trust, London, UK

e-mail: lauradeb@hotmail.com

M. A. Teus

Príncipe de Asturias University Hospital, Alcala de Henares, Madrid, Spain following PRK with a repeat surface ablation procedure.

We are surprised, though, to see how restricted their literature search was. They only report three studies on the matter since 2002, two of them with fewer than four eyes, and they base the need for their study in the lack of recent data on the subject.

PRK is a type of corneal laser surface ablation technique which is very similar to laser-assisted subepithelial keratectomy (LASEK), with the main difference being the repositioning of the epithelial flap over the ablated stroma after LASEK [2]. With the exception of the transepithelial PRK techniques, where the laser ablates through the epithelium before proceeding with the stromal ablation, the de-epithelialization in PRK is done with the application of $18-20 \%$ ethanol over the epithelium, like in LASEK. Results with PRK and LASEK, both using alcohol debridement, have been shown to be similar $[3,4]$. Therefore, when searching for enhancements for PRK, we consider the authors should have included a search for "surface ablation," "LASEK," and "laser subepithelial keratectomy" papers. Had they done so, they would have found a paper published in 2010 by us [5], focused specifically on the results of surface ablation enhancements following previous LASEK, with a sample of 82 eyes. In our study, we focused our discussion on the lack of toxicity with the use of mitomycin $\mathrm{C}$ (MMC) in these 
retreatments. Moshirfar et al. [1] also report using MMC in their series of eyes when the ablation depth was deeper than 65 microns. Similar to those reported by Moshirfar et al., our safety and efficacy indices after enhancement (1.01 and 0.96, respectively) supported, already in 2010, the use of a surface ablation technique for enhancements after previous surface ablation procedures.

\section{ACKNOWLEDGEMENTS}

Funding. No funding or sponsorship was received for this study or publication of this article.

Authorship. All named authors meet the International Committee of Medical Journal Editors (ICMJE) criteria for authorship for this article, take responsibility for the integrity of the work as a whole, and have given their approval for this version to be published.

Authors' Contributions. Concept and design (LDBL, MAT), drafting the manuscript (LDBL, MAT), review and approval of the final version (LDBL, MAT).

Disclosures. The authors of this letter (LDBL, MAT) have no personal, financial, commercial, or academic conflicts of interest to declare.

Compliance with Ethics Guidelines. This article is based on previously conducted studies and does not contain any new studies with human participants or animals performed by any of the authors.

Data Availability. Data sharing is not applicable to this article as no datasets were generated or analyzed during the current study.

Open Access. This article is licensed under a Creative Commons Attribution-
NonCommercial 4.0 International License, which permits any non-commercial use, sharing, adaptation, distribution and reproduction in any medium or format, as long as you give appropriate credit to the original author(s) and the source, provide a link to the Creative Commons licence, and indicate if changes were made. The images or other third party material in this article are included in the article's Creative Commons licence, unless indicated otherwise in a credit line to the material. If material is not included in the article's Creative Commons licence and your intended use is not permitted by statutory regulation or exceeds the permitted use, you will need to obtain permission directly from the copyright holder. To view a copy of this licence, visit http:// creativecommons.org/licenses/by-nc/4.0/.

\section{REFERENCES}

1. Moshirfar M, Villarreal A, Thomson AC, et al. PRK enhancement for residual refractive error after primary PRK: a retrospective study. Ophthalmol Ther. 2021;10:175-85. https://doi.org/10.1007/s40123-02100331-8.

2. Azar DT, Ang RT, Lee JB, Kato T, Chen CC, Jain S, Gabison E, Abad JC. Laser subepithelial keratomileusis: electron microscopy and visual outcomes of flap photorefractive keratectomy. Curr Opin Ophthalmol. 2001;12:323-8.

3. Shah S, Sarhan ARS, Doyle SJ, Pillai CT, Dua HS. The epithelial flap for photorefractive keratectomy. Br J Ophthalmol. 2001;85:393-6.

4. Hashemi H, Fotouhi A, Foudazi H, Sadeghi N, Payvar S. Prospective, randomized, paired comparison of laser epithelial keratomileusis and photorefractive keratectomy for myopia less than - 6.50 diopters. J Refract Surg. 2004;20:217-22.

5. De Benito-Llopis L, Teus MA. Efficacy of surface ablation retreatments using mitomycin C. Am J Ophthalmol. 2010;150(3):376-80. 